\title{
Perancangan Sistem Otomatisasi pada Aquascape Berbasis Mikrokontroller Arduino Nano
}

\author{
Yesi Triawan ${ }^{1}$, Juli Sardi ${ }^{2}$ \\ ${ }^{1}$ Universitas Negeri Padang \\ Jl. Prof Dr. Hamka Air Tawar, Padang \\ yesitriawan52@gmail.com,JuliSardi@ft.unp.ac.id
}

\begin{abstract}
Aquascape is the art of arranging aquatic plants, wood and rocks to form a beautiful landscape with the addition of fish as a companion to balance the ecosystem. The problem that often arises by aquascapers is the continuous time limit for the aquascape so that the ecosystem in it is not disturbed. This study aims to create an automation system in the aquascape which includes offering fish feed, lamp life time, temperature regulation, air temperature regulation, and periodic water changes. This research consisted of making hardware which includes Arduino nano, RTC, DS18B20 sensor, HC-SRO4 sensor and Arduino IDE software as system coding. After conducting experimental experiments, all components in this system are able to work in accordance with the research objectives. The application of an automation system in the aquascape can make it easier for the aquascaper in the care and maintenance of the aquascape.
\end{abstract}

Keywords - Aquascape, automation system, arduino nano, RTC.

\begin{abstract}
Abstrak - Aquascape merupakan seni mengatur tanaman air, kayu dan batu untuk membentuk suatu landscape yang indah dengan tambahan ikan sebagai pendamping untuk menyeimbangkan ekosistem. Permasalahan yang sering dihadapi oleh aquascaper adalah keterbatasan waktu untuk pemantauan secara terus menerus terhadap aquascape agar ekosistem didalamnya tidak terganggu. Penelitian ini bertujuan untuk membuat sistem otomatisasi pada aquascape yang meliputi pemberian pakan ikan, waktu hidup lampu, pengaturan suhu, pengaturan ketinggian air, dan pergantian air secara berkala. Penelitian ini terdiri dari pembuatan perangkat keras (hardware) yang meliputi arduino nano, RTC, sensor DS18B20, serta sensor HC-SR04 dan perangkat lunak (software) Arduino IDE sebagai pengkodean sistem. Setelah dilakukan beberapa percobaan, semua komponen dalam system ini mampu bekerja sesuai dengan tujuan penelitian. Penerapan sistem otomatisasi pada aquascape dapat mempermudah aquascaper dalam hal perawatan dan pemeliharaan aquascape.
\end{abstract}

Kata kunci-Aquascape, sistem otomatisasi, arduino nano, RTC.

\section{Pendahuluan}

Aquascape merupakan seni menata tanaman air, batu karang, dan kayu, sehingga terlihat seperti berkebun di dalam air dengan tambahan ikan sebagai pendamping untuk menyeimbangkan ekosistem[1]. Beberapa faktor yang harus diperhatikan dalam perawatan aquascape adalah suhu air yang harus terjaga dalam rentang suhu 210C - 280C[2], durasi pencahayaan untuk fotosintesis tumbuhan yang berkisar antara 8 sampai 10 jam perhari[3], serta menjaga kebersihan air dengan cara pembersihan kolam aquascape secara berkala. Permasalahan yang sering dihadapi aquascaper adalah keterbatasan waktu untuk pemantauan secara terus menerus terhadap aquascape agar ekosistem didalamnya tidak terganggu[4]. Sehingga penerapan sistem otomatis pada aquascape sangat diperlukan oleh aquascaper untuk memberikan kemudahan dan efisien waktu dalam hal perawatannya.

Sebelumnya sudah ada beberapa penelitian berkaitan dengan aquascpae yang memaparkan tentang penggunaan sensor suhu yang digunakan untuk memantau keadaan suhu didalam air agar tetap dalam kondisi stabil, serta penggunaan cahaya untuk aquascape yang berfungsi sebagai penerangan dan fotosintesis tumbuhan air[5]. Kemudian penelitian yang memaparkan tentang pemantauan kualitas air pada aquascape berdasarkan nilai suhu dan $\mathrm{pH}$ yang akan dijadikan sebagai inputan untuk diproses oleh sistem dengan menggunakan fuzzy logic, sehingga apabila nilainya tidak sesuai dengan parameter yang ditentukan maka air akan dikuras secara otomatis menggunakan water pump[6].

Berdasarkan beberapa penelitian sebelumnya, belum ada sebuah system yang mengatur otomatisasi aquascape secara menyeluruh. Oleh karena itu penulis ingin membuat sebuah system otomatisasi yang dapat mengatur keseluruhan aquascape dengan menggunakan mikrokontroller arduino nano sebagai pemprosesan.

\section{Arduino Nano}

Arduino Nano menggunakan mikrokontroller Atmega 328 untuk Arduino Nano 3.x dan Atmega168 untuk Arduino Nano 2.x. Untuk pembuatan tugas akhir ini penulis menggunakan mikrokontroller ATmega 328. Masing-masing dari 14 pin digital pada Arduino Nano 
dapat digunakan sebagai input atau output, dengan menggunakan fungsi pinMode(), digitalWrite(), dan digitalRead().Arduino Nano memiliki 8 pin sebagai input analog, diberi label A0 sampai dengan A7, yang masingmasing menyediakan resolusi 10 bit (yaitu 1024 nilai yang berbeda). Secara default pin ini dapat diukur/diatur dari mulai Ground sampai dengan 5 Volt.

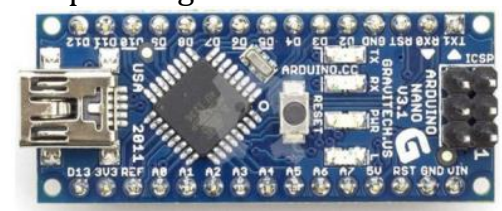

Gambar 1. Arduino Nano

\section{Power Supply}

Power supply adalah perangkat keras yang berfungsi untuk menyuplai tegangan langsung ke komponen dalam cassing yang membutuhkan tegangan. Input power supply berupa arus bolak-balik (AC) sehingga power supply harus mengubah tegangan AC menjadi DC (arus searah).

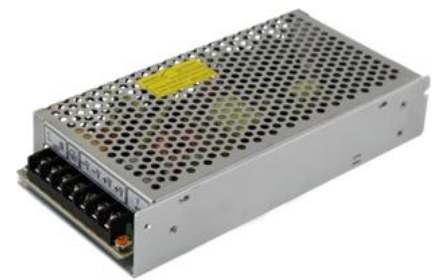

Gambar 2. Power Supply

\section{Sensor Suhu DS18B20}

Sensor suhu DS18B20 merupakan sensor digital yang memiliki 12-bit ADC internal sehingga sangat presisi, sebab sensor ini mampu membaca suhu dengan ketelitian 9 hingga 12 -bit, rentang $-55^{\circ} \mathrm{C}$ hingga $125^{\circ} \mathrm{C}$ dengan ketelitian $\left(+/-0.5^{\circ} \mathrm{C}\right)$. Sensor ini memiliki kode unik sebesar 64-bit yang disematkan pada masing-masing chip, sehingga memungkinkan penggunaan sensor untuk bekerja menggunakan protokol komunikasi 1-wire (onewire).

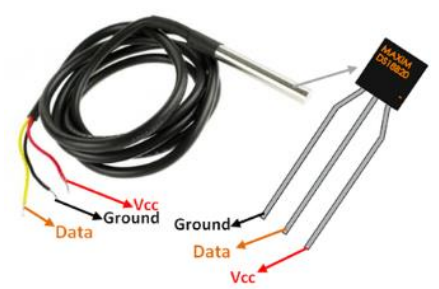

Gambar 3. Sensor Suhu DS18B20

RTC

RTC (Real Time Clock) merupakan jam elektronik berupa chip yang dapat menghitung waktu (mulai detik hingga tahun) dengan akurat dan menjaga/menyimpan data waktu tersebut secara real time. Karena jam tersebut bekerja real time, maka setelah proses hitung waktu dilakukan output datanya langsung disimpan atau dikirim ke device lain melalui sistem antarmuka.

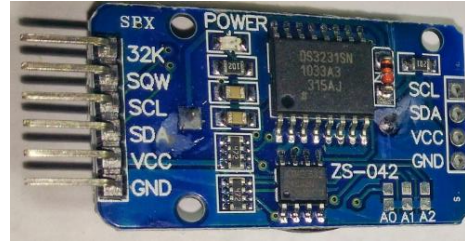

Gambar 4. RTC

\section{Sensor HC-SR04}

Sensor HC-SR04 merupakan sensor ultrasonik yang dapat digunakan untuk mengukur jarak antara penghalang dan sensor. Sensor ultrasonik adalah modul elektronik yang mendeteksi sebuah objek menggunakan suara. Sensor ultrasonic terdiri dari sebuah transmitter (pemancar) dan sebuah receiver (penerima).

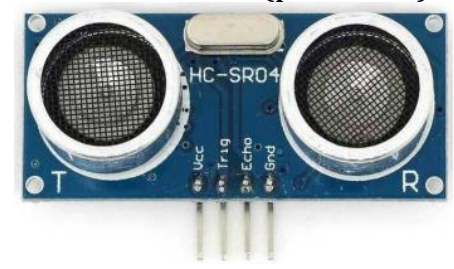

\section{Modul Relay 6 Channel}

Gambar 5. Sensor HC-SR04

Relay merupakan sebuah saklar yang dikendalikan dengan aliran arus listrik. Pada relay terdapat 2 bagian utama yaitu coil dan rangkaian saklar. Relay menggunakan Prinsip Elektromagnetik untuk menggerakkan kontak saklar sehingga dengan arus listrik yang kecil (low power) dapat menghantarkan listrik yang bertegangan lebih tinggi. Jadi ketika terdapat arus listrik yang mengalir pada coil selanjutnya terjadi medan magnet yang akan menarik kemudian melepas plat pada rangkaian saklar dan akan menghubungkan atau memutus arus listriknya.

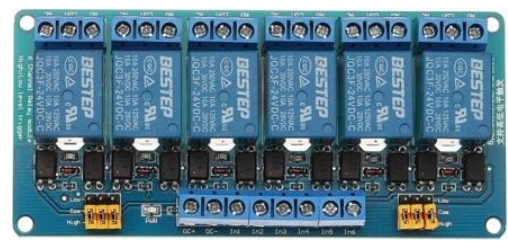

Gambar 6. Modul Relay 6 Channel

\section{Motor Servo}

Motor servo adalah sebuah perangkat atau aktuator putar (motor) yang dirancang dengan sistem kontrol umpan balik loop tertutup (servo), sehingga dapat di set-up atau di atur untuk menentukan dan memastikan posisi sudut dari poros output motor. motor servo merupakan perangkat yang terdiri dari motor DC, serangkaian gear, rangkaian kontrol dan potensiometer.

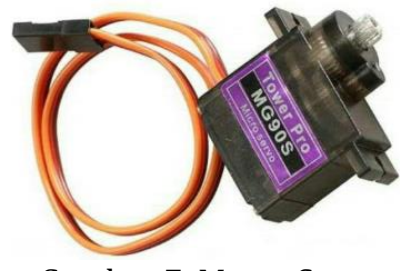

Gambar 7. Motor Servo 


\section{LCD}

LCD (Liquid Cristal Display) berfungsi sebagai penampil data baik dalam bentuk karakter, huruf, angka ataupun grafik.

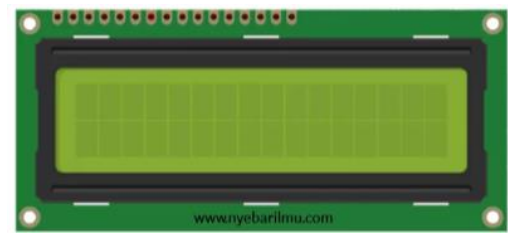

Gambar 8. LCD

\section{METODE}

Metode yang digunakan dalam penelitian ini adalah membuat perangkat hardware sistem otomatisasi pada aquascape serta pelaksanaan percobaan pengujian pada masing-masing komponen.

\section{A. Blok Diagram}

Pada Tugas Akhir ini, perancangan dari sistem otomatisasi pada aquascape berbasis arduino nano terdiri dari beberapa bagian, yaitu: input berupa sensor suhu DS18B20, RTC, sensor jarak HC-SR04, tombol setting, serta output berupa modul relay 6 channel, motor servo, dan LCD. Berikut blok diagram keseluruhan seperti dibawah ini.

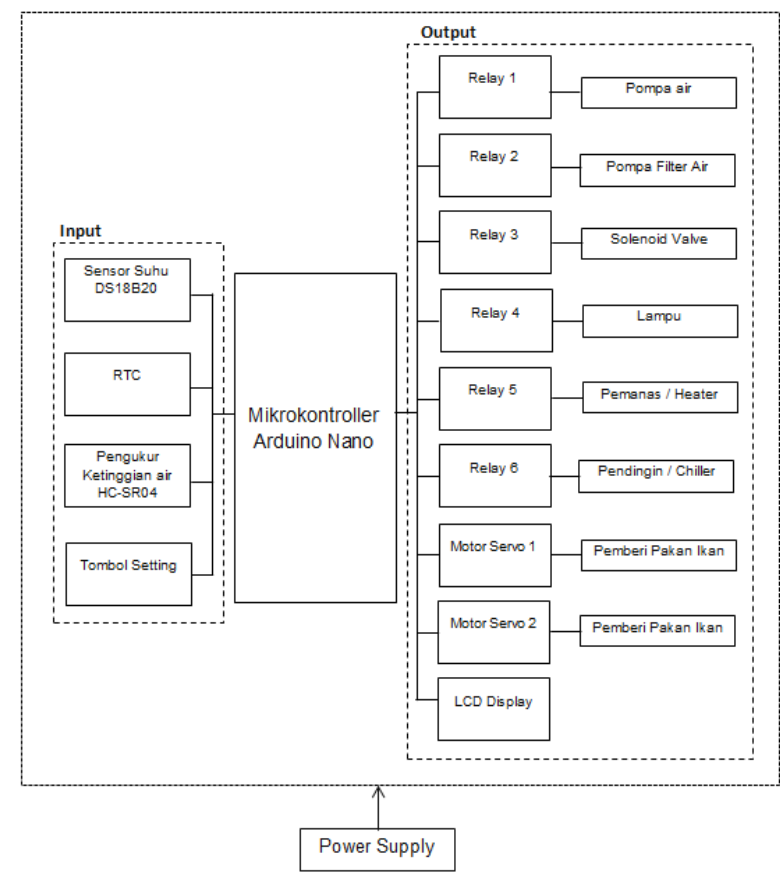

Gambar 9. Blok Diagram Keseluruhan

Berdasarkan blok diagram keseluruhan sistem di atas, fungsi dari masing-masing komponen sebagai berikut:

a. Arduino Nano merupakan mikrokontroler dengan chip Atmega 328, pada system aquas cape mikrokontroler ini berfungsi sebagai pemproses input dan output pada rangkaian mengolah data sehingga alat dapat berfungsi seperti pada tujuan perancangan alat.

b. Power Supply switching $12 \mathrm{~V} 3 \mathrm{~A}$ berfungsi sebagai penyuplai sumber tegangan ke masingmasing rangkaian.

c. Modul relay berfungsi sebagai driver untuk menghubungkan dua buah perangkat dengan tegangan kerja yang berbeda-beda sehingga mikrokontroler yang tegangan kerjanya hanya $5 \mathrm{vdc}$ dapat mengontrol peralatan yang menggunakan tegangan kerja serta arus yang lebih besar.

d. Motor Servo digunakan sebagai alat untuk menggerakan tempat pakan ikan yang diletakkan disisi samping aquascape.

e. RTC berfungsi sebagai modul timer (pewaktuan) sebagai acuan untuk waktu pemberian pakan ikan, waktu hidup dan mati lampu aquascape, serta jadwal pembersihan kolam.

f. Sensor DS18B20 berfungsi untuk mengetahui suhu air didalam aquascape, Data suhu dari sensor akan menjadi acuan untuk mengontrol suhu air secara otomatis menggunakan pemanas atau pendingin air, sesuai kebutuhan sistem aquascape.

g. Tombol setting digunakan untuk mengatur input pada sistem otomatisasi aquascape.

h. Sensor HC-SR04 berfungsi untuk mengukur ketinggian air kolam aquascape.

i. Lampu pada aquascape berfungsi sebagai penerangan serta untuk fotosintesis tanaman.

j. Pompa air yang digunakan untuk tugas akhir ini adalah pompa air celup, berfungsi untuk menguras air didalam aquascape pada saat penggantian air.

k. Pompa filter air berfungsi untuk melakukan pembersihan air kolam secara terus menerus setiap harinya.

l. Solenoid kran air berfungsi sebagai pengatur buka dan tutup kran air masuk pada saat penggantian air aquascape, sehingga pada saat penggantian air, pemilik aquascape cukup menghubungkan selang air dengan input dari solenoid kran air, system akan melakukan pergantian air secara otomatis dan akan berhenti ketika air kolam sudah sampai pada ambang batas yang ditentukan.

m. Pendingin atau chiller berfungsi untuk menjaga kondisi suhu air tetap stabil, akan aktif apabila suhu berada diatas $27^{\circ} \mathrm{C}$.

n. Pemanas atau heater berfungsi untuk menjaga kondisi suhu air tetap stabil, akan aktif apabila suhu berada dibawah $22^{\circ} \mathrm{C}$.

o. LCD digunakan sebagai output untuk menampilkan informasi data sistem otomatisasi aquascape. 


\section{B. Flowchart}

Prinsip kerja dari alat ini dijelaskan melalui suatu gambar atau bagan yang menunjukkan langkah atau urutan suatu program. Flowchart untuk sistem otomatisasi aquascape ditunjukkan pada gambar 2 .

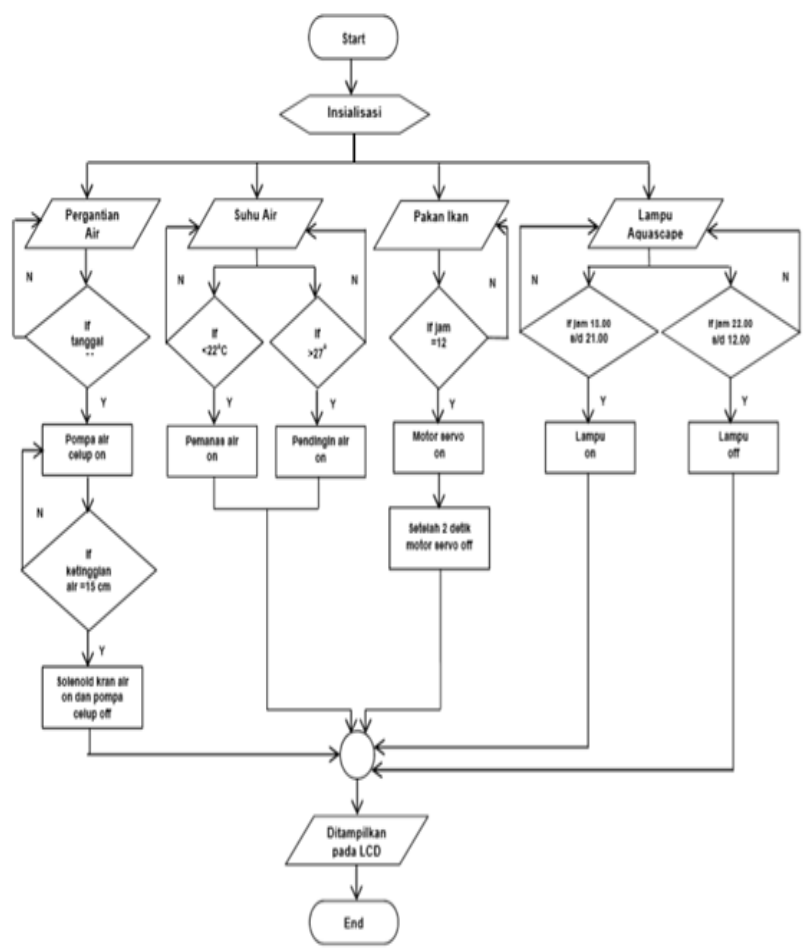

Gambar 10. Flowchart

Pada gambar 10 diatas merupakan flowchart atau diagram alur cara kerja alat secara keseluruhan, Sistem diawali dengan inisialisasi port, kemudian sistem akan mendeteksi masing-masing keadaan.

\section{Perancangan Hardware}

Perancangan hardware merupakan suatu tahapan atau proses dalam pembuatan suatu perangkat keras. Perancangan hardware bertujuan untuk memudahkan serta mengurangi tingkat kesalahan dalam membuat perangkat keras sehingga mendapatkan hasil yang optimal. Rancangan wadah aquascape seperti gambar 11 dan rancangan box elektronika pada gambar 12 .

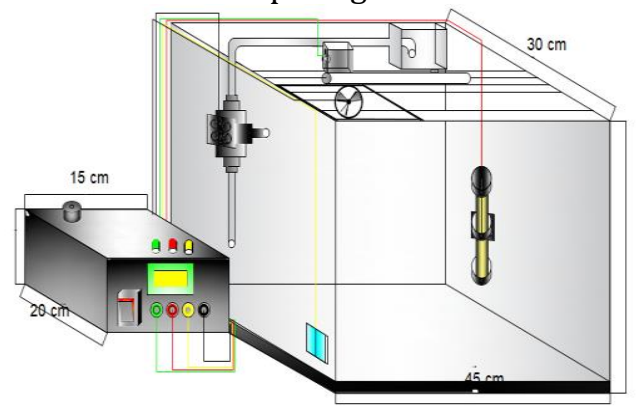

Gambar 11. Rancangan Wadah Aquascape

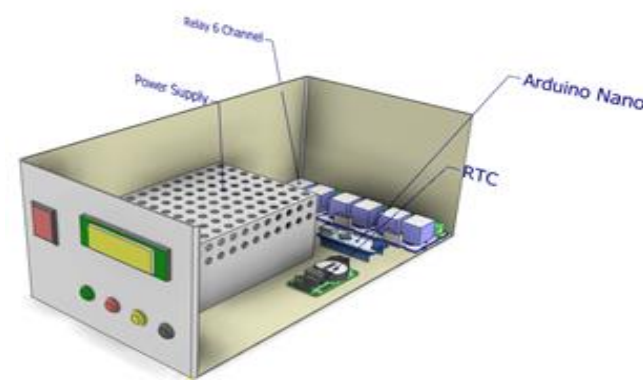

Gambar 12. Rancangan Box Elektronika

\section{Perancangan Software}

Perancangan software secara keseluruhan pada tugas akhir ini menggunakan Arduino IDE (Integrated Development Environment), yaitu software yang merupakan bawaan dari arduino itu sendiri, sehingga dapat mengendalikan seluruh input dan output yang digunakan pada sistem otomatisasi aquascape. Pada software Arduino IDE dapat dilakukan proses compile dan upload program yang dibuat ke dalam mikrokontroler arduino. Kode - kode program arduino dibuat menggunakan bahasa pemrograman C. Untuk komunikasi antara perangkat dengan pengguna, penulis menggunakan tombol yang berfungsi untuk memberikan input untuk mengatur kontrol otomatis pada aquascape, serta hasil dari pengaturan akan ditampilkan melalui LCD.

\section{HASIL DAN PEMBAHASAN}

Pada bagian ini dilakukan pegujian dan pembahasan untuk seluruh bagian input dan output. Pengujian dan pembahasan dilakukan untuk mengetahui sistem otomatisasi aquascape dapat berfungsi dengan baik atau tidak sesuai dengan rancangan. Pengujian sistem otomatisasi aquascape meliputi pengujian sensor suhu DS18B20 yang berfungsi untuk memantau keaadan suhu didalam air, dimana hasil dari pembacaan sensor suhu akan menjadi acuan untuk mengotrol suhu secara otomatis menggunakan pemanas atau pendingin, pengujian sensor jarak HC-SR04 yang berfungsi untuk mengukur ketinggian air kolam aquascape pada saat proses pergantian air, RTC yang berfungsi sebagai modul pewaktuan untuk waktu pemberian pakan ikan yang akan digerakkan oleh motor servo, waktu hidup atau mati lampu, serta jadwal pergantian air, dan tombol setting yang digunakan untuk mengatur input pada sistem otomatisasi aquascape,dimana setiap langkah input dapat dilihat melalui LCD.

\section{A. Pengujian Hardware}

1. Pengujian Rangkaian Sensor Jarak

Penggunaan sensor jarak berfungsi untuk mengetahui ketinggian air yang ada didalam wadah aquascape. Pengujian sensor jarak bertujuan untuk mengetahui tingkat akurasi pembacaan sensor dan error dari data hasil pengukuran sensor jarak. Untuk menguji rangkaian 
dari sensor jarak, didalam wadah aquascape diletakkan sebuah busa yang mengapung, sehingga pantulan dari busa akan menjadi acuan dalam pembacaan sensor. Pengujian sensor jarak akan dilakukan menggunakan sensor HC-SR04 dan sebagai pembanding, penulis menggunakan mistar untuk pengujian sebenarnya. Perbandingan pengujian sensor jarak dan mistar dapat dilihat pada tabel 1 .

Ragam ralat dari pengukuran atau pengamatan dibagi menjadi 3 macam, yaitu ralat sistematis (systematic error), ralat rambang (random error), dan ralat kekeliruan tindakan[7]. Ralat sistematis adalah ralat pengukuran yang akan memberikan efek tetap terhadap hasil ukur. Rumus perhitungan nilai error :

$$
\text { Error }=|\mathrm{X}-\mathrm{Xi}|
$$

$$
\% \text { Error }=\left|\frac{(\mathrm{X}-\mathrm{Xi})}{\mathrm{X}}\right| \mathrm{x} 100 \%
$$

Keterangan :

$\mathrm{X}=$ Data Sebenarnya

$\mathrm{Xi}=$ Data Terukur

$\%$ Error $=$ Ralat Sistematis

Selanjutnya dapat dijabarkan untuk mencari error dan menghitung \% error yaitu :

Error $=\mid$ jarak sebenarnya - jarak terukur $\mid$

$\%$ Error $=\left|\frac{(\text { Jarak Sebenarnya }- \text { Jarak Terukur })}{\text { Jarak Sebenarnya }}\right| \times 100 \%$

Tabel I. Data Hasil Pengujian Sensor Jarak

\begin{tabular}{|c|c|c|c|}
\hline $\begin{array}{c}\text { Pengujian } \\
\text { dengan } \\
\text { Mistar } \\
(\mathrm{Cm})\end{array}$ & $\begin{array}{c}\text { Pengujian } \\
\text { dengan Sensor } \\
\text { HC-SR04 } \\
(\mathrm{Cm})\end{array}$ & $\begin{array}{c}\text { Selisih } \\
\text { Error }\end{array}$ & \% Error \\
\hline 6,2 & 6 & 0,2 & 3,2 \\
\hline 7,2 & 7 & 0,2 & 2,7 \\
\hline 8,1 & 8 & 0,1 & 1,2 \\
\hline 9,2 & 9 & 0,2 & 2,1 \\
\hline 10,2 & 10 & 0,2 & 1,9 \\
\hline \multicolumn{3}{|c|}{ Rata-rata error } \\
\hline
\end{tabular}

Berdasarkan pengujian yang telah dilakukan, terlihat bahwa sensor jarak HC-SR04 dapat bekerja dengan baik sebagai pengukuran ketinggian. Hal tersebut dapat dilihat dari akurasi sensor pengukuran jarak sebesar 97,73\% .

\section{Pengujian Rangkaian Sensor Suhu DS18B20}

Pengujian rangkaian sensor suhu berfungsi untuk mengetahui tingkat akurasi dan error dari data hasil pengukuran sensor suhu[8]. Pengujian rangkaian sensor suhu akan menggunakan sensor DS18B20 dan sebagai pembanding, penulis menggunakan sensor Thermo Gun untuk pembacaan suhu sebenarnya. Pengamatan nilai sensor suhu DS18B20 akan tampil pada LCD. Perbandingan pengujian sensor suhu dapat dilihat pada tabel 2. Rumus untuk mencari error dan menghitung \% error yaitu :
Error $=\mid$ jarak sebenarnya - jarak terukur $\mid$

$$
\% \text { Error }=\left|\frac{(\text { Jarak Sebenarnya -Jarak Terukur })}{\text { Jarak Sebenarnya }}\right| \times 100 \%
$$

Tabel II. Data Hasil Pengujian Sensor Suhu

\begin{tabular}{|c|c|c|c|}
\hline $\begin{array}{c}\text { Pembacaan } \\
\begin{array}{c}\text { Suhu Thermo } \\
\text { Gun } \\
\left({ }^{\circ} \mathrm{C}\right)\end{array}\end{array}$ & $\begin{array}{c}\text { Pembacaan Suhu } \\
\text { DS18B20 } \\
\left({ }^{\circ} \mathrm{C}\right)\end{array}$ & Selisih Error & \% Error \\
\hline 10,2 & 10 & 0,2 & 1,9 \\
\hline 15,3 & 15 & 0,3 & 1,9 \\
\hline 20,1 & 20 & 0,1 & 0,4 \\
\hline 25,4 & 25 & 0,4 & 1,5 \\
\hline 30,1 & 30 & 0,1 & 0,3 \\
\hline \multicolumn{3}{|c|}{ Rata-rata error } \\
\hline
\end{tabular}

Berdasarkan pengujian yang telah dilakukan terlihat bahwa sensor suhu DS18B20 dapat bekerja dengan baik. Hal ini dapat dilihat dari akurasi pembacaan sensor suhu DS18B20 sebesar 98,74\%.

3. Pengujian Pengujian Pergerakan Motor Servo dalam Pemberian Pakan Ikan

Pengujian pemberian pakan ikan berfungsi untuk memberikan pakan ikan secara otomatis. Waktu pemberian pakan ikan diatur menggunakan RTC dan wadah penyimpanan pakan akan digerakkan menggunakan motor servo. Pada pengujian ini, pemberian pakan ikan diatur setiap jam 12.00 untuk setiap harinya. Wadah tempat pakan ikan dapat menyimpan pakan sekitar 10 gr. Pengujian pemberian pakan ikan bertujuan untuk menentukan posisi servo yang ideal untuk menumpahkan pakan ikan, sehingga banyak pakan yang tumpah sesuai dengan kebutuhan ikan. Hasil dari pengujian pemberian pakan ikan dapat dilihat pada tabel 3 .

Tabel III. Pengujian Pemberian Pakan Ikan

\begin{tabular}{|c|c|c|c|l|}
\hline No & $\begin{array}{c}\text { Derajat } \\
\text { Servo }\end{array}$ & $\begin{array}{c}\text { Sketsa Kondisi } \\
\text { Mekanik } \\
\text { Pakan }\end{array}$ & $\begin{array}{c}\text { Jumlah } \\
\text { Pakan } \\
\text { yang } \\
\text { Tumpah }\end{array}$ & Keterangan \\
\hline 1 & 00 & & 0 gr & $\begin{array}{l}\text { Kondisi pakan } \\
\text { tidak tumpah }\end{array}$ \\
\hline 2 & $60^{0}$ & 0 gr & $\begin{array}{l}\text { Kondisi pakan } \\
\text { tidak tumpah }\end{array}$ \\
\hline 3 & $90^{0}$ & $0,01 \mathrm{gr}$ & $\begin{array}{l}\text { Kondisi pakan } \\
\text { tumpah sedikit }\end{array}$ \\
\hline 5 & $150^{\circ}$ & & $0,1 \mathrm{gr}$ & $\begin{array}{l}\text { Kondisi pakan } \\
\text { tumpah secara } \\
\text { maksimal }\end{array}$ \\
\hline
\end{tabular}


Berdasarkan pengujian yang telah dilakukan, kondisi ideal untuk pemberian pakan ikan berada saat posisi motor servo 1200. Pada saat motor servo berada pada posisi 00600 dan 900 pakan ikan tumpah cenderung sedikit sehingga tidak mencukupi untuk kebutuhan ikan, namun pada posisi 1500 pakan ikan tumpah terlalu banyak dan melebihi kebutuhan ikan. Jadi posisi ideal untuk pemberian pakan ikan adalah saat motor servo berada pada posisi 1200 , jumlah pakan ikan yang tumpah sesuai dengan kebutuhan ikan didalam kolam aquascape.

\section{Pengujian Pergantian Air}

Pengujian pergantian air berfungsi untuk proses pembersihan air kolam aquascape. Pada proses ini, air kolam aquascape akan dibuang menggunakan pompa celup dan disisakan sekitar $\pm 11 \mathrm{~cm}$ agar ekosistem didalam air tidak terganggu saat proses penggantian air. Ketika ketinggian air sudah sesuai, maka solenoid valve akan membuka dan mengalirkan air sehingga kolam aquascape akan terisi kembali. Batas pengisian kolam aquascape akan dipantau oleh sensor jarak, ketika batas maksimum pengisian air sudah sesuai maka solenoid valve akan menutup. Pengujian pergantian air aquascape dapat dilihat pada tabel 4 .

Tabel IV. Pengujian Pergantian Air

\begin{tabular}{|c|c|l|c|c|}
\hline $\begin{array}{c}\text { Waktu } \\
\text { Pergantian } \\
\text { Air }\end{array}$ & $\begin{array}{c}\text { Ketinggian } \\
\text { Air }\end{array}$ & $\begin{array}{l}\text { Kondisi Saat } \\
\text { Pergantian } \\
\text { Air }\end{array}$ & $\begin{array}{c}\text { Kondisi } \\
\text { Pompa } \\
\text { Celup }\end{array}$ & $\begin{array}{c}\text { Kondisi } \\
\text { Solenoid } \\
\text { Valve }\end{array}$ \\
\hline $17.09 \mathrm{WIB}$ & $28 \mathrm{~cm}$ & $\begin{array}{l}\text { Kondisi awal } \\
\text { saat } \\
\text { memulai } \\
\text { pergantian } \\
\text { air }\end{array}$ & On & Off \\
\hline $17.15 \mathrm{WIB}$ & $11 \mathrm{~cm}$ & $\begin{array}{l}\text { Batas } \\
\text { minimum } \\
\text { pengurasan } \\
\text { air }\end{array}$ & Off & On \\
\hline $18.09 \mathrm{WIB}$ & $28 \mathrm{~cm}$ & $\begin{array}{l}\text { Batas } \\
\text { maksimum } \\
\text { pengisian air }\end{array}$ & Off & Off \\
\hline
\end{tabular}

Berdasarkan pengujian yang telah dilakukan pada proses pergantian air, waktu yang diperlukan untuk pembersihan kolam aquascape secara menyeluruh sekitar \pm 1 jam dan masing-masing komponen dapat bekerja dengan baik sebagaimana fungsinya. Pengaturan kerja komponen disesuaikan dengan ketinggian air aquascape, sehingga proses pergantian air berjalan dengan baik dan tidak terjadi kesalahan.

\section{Pengujian Pertumbuhan Tanaman}

Pengujian pertumbuhan tanaman berfungsi untuk mengetahui pengaruh pemberian cahaya terhadap pertumbuhan tanaman aquascape[9]. Pengujjian dilakukan selama 7 hari terhitung semenjak penumbuhan bibit. Penulis menggunakan tanaman jenis dwarf tears baby[10], yang diuji dengan memberikan dua macam keadaan, yang pertama tanpa cahaya dan keadaan kedua pemberian cahaya sekitar 8 jam perhari. Perbandingan bentuk pertumbuhan tanaman dapat dilihat pada tabel 5 .

Tabel V. Pengujian Pertumbuhan Tanaman

\begin{tabular}{|l|c|c|c|c|c|c|c|c|}
\hline \multirow{2}{*}{ Pengujian } & \multicolumn{5}{|c|}{ Pertumbuhan Tanamn } & \multicolumn{1}{c|}{ Bentuk } \\
\cline { 2 - 8 } & $\begin{array}{l}\text { Hari } \\
\text { ke-1 }\end{array}$ & $\begin{array}{l}\text { Hari } \\
\text { ke-2 }\end{array}$ & $\begin{array}{l}\text { Hari } \\
\text { ke-3 }\end{array}$ & $\begin{array}{l}\text { Hari } \\
\text { ke-4 }\end{array}$ & $\begin{array}{l}\text { Hari } \\
\text { ke-5 }\end{array}$ & $\begin{array}{l}\text { Hari } \\
\text { ke-6 }\end{array}$ & $\begin{array}{l}\text { Hari } \\
\text { ke-7 }\end{array}$ & Batang \\
\hline $\begin{array}{l}\text { Keadaan } \\
\text { tanpa } \\
\text { cahaya }\end{array}$ & 0 & 0 & 0,1 & 1,5 & 3 & 4 & 5,5 & $\begin{array}{l}\text { Miring ke } \\
\text { samping }\end{array}$ \\
\hline $\begin{array}{l}\text { Keaadan } \\
\text { dengan } \\
\text { ahaya 8 } \\
\text { jam/hari }\end{array}$ & 0 & 0 & 0,5 & 1 & 2 & 3 & 3,5 & $\begin{array}{l}\text { Tegak } \\
\text { arus ke } \\
\text { atas }\end{array}$ \\
\hline
\end{tabular}

Berdasarkan pengujian yang telah dilakukan, tanaman yang diberikan cahaya sekitar 8 jam perhari lebih baik pertumbuhannya dibandingkan tumbuhan yang tidak diberikan cahaya. Dapat dilihat perbedaan pertumbuhan tanaman berdasarkan waktunya, dimana pada hari ketiga dalam kondisi tanpa cahaya, tanaman tumbuh sedikit lebih lambat dibandingkan dengan tanaman yang diberikan cahaya. Pada hari selanjutnya, tanaman dengan kondisi tanpa cahaya tumbuh lebih panjang, sedangkan tanaman yang diberikan cahaya lebih pendek pertumbuhannya. Dalam arah rambatannya, tanaman tanpa cahaya tumbuh dengan posisi miring, sedangkan tanaman dengan cahaya tumbuh dengan posisi lurus tegak ke atas.

\section{B. Pengujian Software}

\section{Program pengaturan suhu \\ Berikut list programnya :}

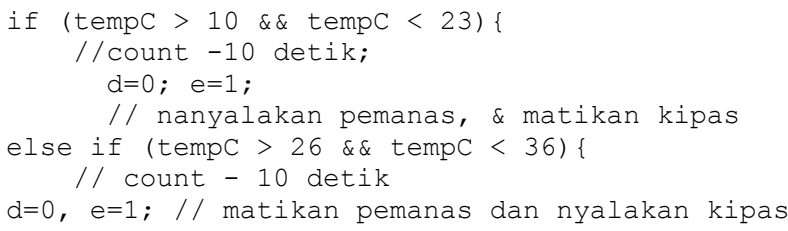

Pada kode program tempC berfungsi untuk menyimpan nilai suhu yang dibaca oleh sensor suhu DS18B20, sehingga menjadi acuan untuk on/off pemanas dan kipas.

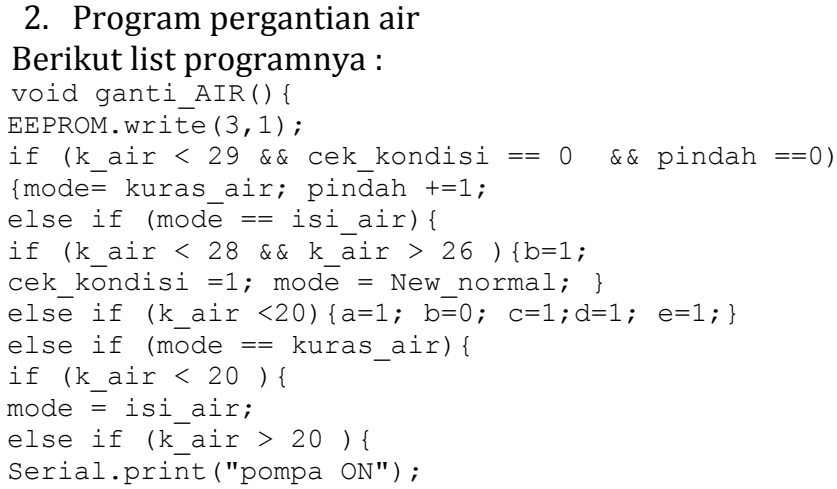


Pada kode program EEPROM.write berfungsi untuk menyimpan data pergantian air dalam memori arduino. Pada Serial.print berfungsi untuk menampilkan informasi pada layar LCD.

3. Program untuk pemberian pakan ikan

Berikut list programnya :

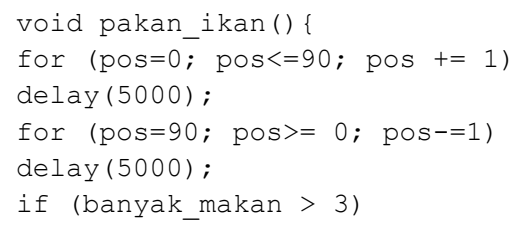

Pada kode program pos berfungsi untuk menentukan posisi derajat kemiringan servo. Pada kode program delay(5000) bertujuan untuk mengisntruksikan program akan berjalan selama 5 detik.

4. Program untuk pengaturan lampu

Berikut listing programnya :

else if ( data lamp on $==$ now.hour ()) EEPROM.write $(3,0)$; delay (2000);

else if ( data lamp off $==$ now.hour ()) \{ EEPROM.write $(3,1)$; delay $(2000)$.

Pada kode program data_lamp_on berfungsi sebagai perintah untuk menyalakan lampu berdasarkan jam yang ditentukan. Pada data_lamp_off berfungsi sebagai perintah untuk mematikan lampu sesuai jam yang ditentukan EEPROM.write berfungsi untuk menyimpan data pewaktuan untuk on/off lampu aquascape.

\section{Pengujian Alat Secara Keseluruhan}

Adapun tujuan pengujian ini untuk melihat sejauh mana hasil dari kerja alat sistem otomatisasi aquascape, sehingga didapat hasil dan perbandingan dari apa yang direncanakan sebelumnya. Pada tahap ini, alat akan dioperasikan secara normal dengan menghubungkan ke kontak listrik. Pengujian alat secara keseluruhan dapat dilihat pada tabel 6 .

Tabel VI. Pengujian Alat Keseluruhan

\begin{tabular}{|c|c|c|l|}
\hline $\begin{array}{c}\text { Nama } \\
\text { Komponen }\end{array}$ & Berfungsi & $\begin{array}{c}\text { Tidak } \\
\text { Berfungsi }\end{array}$ & \multicolumn{1}{|c|}{ Keterangan } \\
\hline $\begin{array}{c}\text { Sensor HC- } \\
\text { SR04 }\end{array}$ & $\sqrt{ }$ & - & $\begin{array}{l}\text { Sensor berfungsi } \\
\text { dengan baik untuk } \\
\text { memantau ketinggian } \\
\text { air. }\end{array}$ \\
\hline $\begin{array}{c}\text { Sensor } \\
\text { DS18B20 }\end{array}$ & $\sqrt{ }$ & - & $\begin{array}{l}\text { Sensor berfungsi } \\
\text { dengan baik untuk } \\
\text { memantau suhu } \\
\text { didalam air. }\end{array}$ \\
\hline Motor servo & $\sqrt{ }$ & - & $\begin{array}{l}\text { Motor servo bergerak } \\
\text { dengan baik untuk } \\
\text { menggerakkan tempat } \\
\text { pakan ikan. }\end{array}$ \\
\hline
\end{tabular}

\begin{tabular}{|c|c|c|l|}
\hline Lampu & $\sqrt{ }$ & - & $\begin{array}{l}\text { Lampu dapat bekerja } \\
\text { dengan baik. }\end{array}$ \\
\hline Heater & $\sqrt{ }$ & - & $\begin{array}{l}\text { Heater bekerja dengan } \\
\text { baik berdasrkan } \\
\text { keaadam suhu didalam } \\
\text { aquascape. }\end{array}$ \\
\hline Chiller & $\sqrt{ }$ & - & $\begin{array}{l}\text { Chiller bekerja dengan } \\
\text { dengan baik berdasrkan } \\
\text { keadaan suhu didalam } \\
\text { aquascape. }\end{array}$ \\
\hline $\begin{array}{c}\text { Pompa filter } \\
\text { air }\end{array}$ & $\sqrt{ }$ & - & $\begin{array}{l}\text { Pompa filter air } \\
\text { berfungsi dengan baik } \\
\text { untuk menyaring air } \\
\text { aquascape. }\end{array}$ \\
\hline Pompa celup & $\sqrt{ }$ & - & $\begin{array}{l}\text { Pompa celup berfungsi } \\
\text { dengan baik untuk } \\
\text { menguras air aquascape } \\
\text { pada proses pergantian } \\
\text { air. }\end{array}$ \\
\hline Solenoid valve & $\sqrt{ }$ & - & $\begin{array}{l}\text { Solenoid valve berfungsi } \\
\text { dengan baik untuk meng } \\
\text { air aquascape pada prose } \\
\text { pergantian air. }\end{array}$ \\
\hline
\end{tabular}

\section{KESIMPULAN}

Berdasarkan hasil pengujian terhadap pembuatan sistem otomatisasi aquascape, maka diperoleh kesimpulan alat ini mampu melakukan sistem otomatisasi pada aquascape secara keseluruhan yang meliputi pemberian pakan ikan, waktu hidup lampu, pengaturan suhu, serta pengaturan ketinggian air. Setiap komponen pada alat ini dapat bekerja dengan baik sesuai fungsinya masingmasing.

\section{REFERENSI}

[1] B. Santoso and A. D. Arfianto, "Sistem Pengganti Air Berdasarkan Kekeruhan Danpemberi Pakan Ikan Pada Akuarium Air Tawar Secara Otomatis Berbasis Mikrokontroler ATMEGA 16," J. Ilm. Teknol. Inf. Asia, vol. 8, no. 2, pp. 33-48, 2014.

[2] A. Razo and H. Aprilianto, "Alat Penyiram Tanaman Aquascape Otomatis Berbasis Arduino Uno Dan Monitoring Berbasis Mobile," Progresif J. Ilm. Komput., 2019.

[3] D. E. Putra, "Rancang Bangun Kontrol Suhu Dan Cahaya Pada Aquascape Berbasis Mikrokontroler," pp. 1-8, 2019.

[4] A. Brahmantika, "Sistem Otomatisasi Budidaya Tumbuhan Aquascape Berbasis Arduino UNO," Semin. Has. Elektro S1 ITN Malang, pp. 1-14, 2019.

[5] Fauzi Kurnia, "Rancangan Bangun Sistem Otomatisasi Pengendalian Suhu dan Cahaya Pada Seni Aquascape," 2014.

[6] M. S. A, A. G. Putrada, and N. A. Suwastika, "Implementasi dan Analisis Pengurasan Otomatis Aquascape Berdasarkan Kualitas Air Menggunakan Fuzzy Logic," e-Proceeding Eng., vol. 6, no. 1, pp. 2091-2099, 2019, doi: 2355-9365.

[7] S. Raharjo, E. Kurniawan, and E. D. Nurcahya, "SISTEM OTOMATISASI FOTOSINTESIS BUATAN PADA AQUASCAPE BERBASIS ARDUINO," KOMPUTEK, 2018, doi 10.24269/jkt.v2i1.66.

[8] F. R. Nurlianisa, "Kit Aquascape Berbasis Internet of Things Melalui Aplikasi Blynk dengan Arduino Uno Untuk Pemeliharaan Lilaeopsis Brasiliensis," 2018. 
[9] P. N. Lhokseumawe, K. Pengantar, rahayu deny danar dan alvi furwanti Alwie, A. B. Prasetio, and R. Andespa, "Perancangan Alat Pemberian Pupuk Cair Aquascape Otomatis," J. Ekon. Vol. 18, Nomor 1 Maret201, vol. 2, no. 1, pp. 41-49, 2010.

[10] M. Kurniawan et al., "Kandungan Klorofil, Karotenoid, dan Vitamin C pada Beberapa Spesies Tumbuhan Akuatik," Kandung. Klorofil, Karotenoid, dan Vitam. C pada Beberapa Spesies Tumbuh. Akuatik, vol. 18, no. 1, 2010, doi: 10.14710/baf.v18i1.2614.

\section{Biodata Penulis}

Yesi Triawan, lahir di Padang, 8 Desember 1997. Menyelesaikan studi DIV Teknik Elektro Industri pada Jurusan Teknik Elektro Fakultas Teknik Universitas Negeri Padang.

Juli Sardi, S.Pd, M.T, lahir di Dhamasraya, 18 Juli 1987. Menyelesaikan studi S1 di Universitas Negeri Padang tahun 2010. Pendidikan S2 di Institut Tekneologi Sepuluh Nopember tahun 2013. Saat ini terdaftar sebagai dosen pengajar pada jurusan teknik elektro Universitas Negeri Padang. 